\title{
Individual Monitoring of Internal Exposure for Nuclear Medicine Workers in NINMAS through In-Vitro Bioassay Techniques
}

\author{
Mahadee Hasan Shubho', Md. Mahidul Haque Prodhan', Ferdoushi Begum², Md. Hossain Sahadath', Md. Zakir Hossain ${ }^{3}$ \\ and Jannatul Ferdous ${ }^{3}$ \\ 'Department of Nuclear Engineering University of Dhaka, Bangladesh \\ ${ }^{2}$ National Institute of Nuclear Medicine and Allied sciences, BAEC, Bangladesh \\ ${ }^{3}$ Heath physics Division, AECD, BAEC, Bangladesh
}

Correspondence Address: Jannatul Ferdous, Principal scientific officer, Heath physics division, Atomic Energy Centre, BAEC, Dhaka- 1000, Bangladesh. ferdous28@yahoo.com

\begin{abstract}
Internal radiation monitoring of occupational radiation workers is essential for protecting them against the risks of incorporated radionuclides. More than 400 workers in Bangladesh are working with unsealed radioactive sources and most of them are employed at different nuclear facilities. Among the 18 Nuclear Medicine Centers in the country, the National Institute of Nuclear Medicine and Allied Science (NINMAS), Dhaka was selected for this study where workers get internal radiation exposure while processing and labeling of the liquid sources. The aim of this study was to estimate the activity concentration and committed effective doses from bioassay sample, namely urine samples of Nuclear Medicine (NM) workers due to handling of radioactive Iodine (131I), Technetium (99mTc) and Fluorine (F-18). Total 86 urine samples were collected from 17 occupational workers of NINMAS during the year 2017 and analyzed using High Purity Germanium (HPGe) detector. The radioactivity of ${ }^{131} \mathrm{I}$ and $\left({ }^{99 m} \mathrm{Tc}\right)$ was found $2.21 \pm 0.44 \mathrm{BqL}^{-1}$ to $444 \pm$ $39.91 \mathrm{BqL}^{-1}$ and $5.53 \pm 1.12 \mathrm{BqL}^{-1}$ to $603 \pm 72.36 \mathrm{BqL}^{-1}$ respectively. Due to low activity of the unsealed F-18 sources and for appropriate shielding, radioactivity of F-18 was found below the minimum detection level in the urine samples of the workers who handled it. The effective doses of occupational workers have also been calculated using the radioactivity concentration and the dose coefficients given in ICRP publication 78. The highest and lowest effective doses due to handling of the unsealed source of $\left({ }^{99 \mathrm{mTc})}\right.$ were 28.2 and $0.0258 \mu \mathrm{Sv}$ for working with 780 and $36 \mathrm{mCi}$ of radionuclide respectively. On the other hand, the highest and lowest effective doses due to handling of ${ }^{131} \mathrm{I}$ were 8.73 and $0.045 \mu \mathrm{Sv}$, for working with 1425 and $55 \mathrm{mCi}$ respectively. Both the doses are found to comply with ICRP annual dose limit of $20 \mathrm{mSv}$.
\end{abstract}

Key words: High Purity Germanium (HPGe) detector, Radioactivity, Minimum Detection Level, ICRP.

Bangladesh J. Nucl. Med. Vol. 22 No. 2 July 2019

Doi: https://doi.org/10.3329/bjnm.v22i2.51763

\section{INTRODUCTION}

The use of radioisotopes in Nuclear Medicine (NM) is increasing continuously over the last few decades. When occupational workers of NM handle unsealed radioactive sources, it poses significant risks of internal exposure. Radioactive Iodine (131I), Technetium (99mTc) and Fluorine (F-18) are common radio-isotopes which are widely applied in NM both in Bangladesh and around the globe. Half-life of 131 I, a volatile radionuclide is about 8.3 days which undergoes negative $\beta$ decays. 131I solutions are easily oxidized at normal temperature, which may expose the skin or inhalation from gaseous iodine will result in internal contamination. About $30 \%$ is deposited in thyroid and $70 \%$ is deposited in the body (1). ${ }^{99 \mathrm{mTc}}$ is not as volatile as ${ }^{131 \mathrm{I}}$ and widely used for diagnostic imaging. Its effective half-life is very short about 6 hours. The internal radiation risk that it poses may sometimes be overlooked (2). Fluorine-18 has a very short half life of 109.8 minutes and not suitable for rigorous inventory tracking, hence, storage at the point of use should be ensured. F-18 may pose a radiological hazard by external and internal exposure.

For thyroid diseases, 131I is used for diagnostic and therapeutic purpose (3-5). When occupational workers process and labels the unsealed liquid sources with labeling compounds, the sources may enter their systems through inhalation and ingestion. The present study was aimed to measure the contamination of the occupational staff who handle the above mentioned 
radiopharmaceuticals. A standard monitoring program for workers occupationally exposed to ${ }^{131} \mathrm{I}, 99 \mathrm{mTc}$ and F-18 should include direct thyroid measurement, indirect bioassay of urine samples and workplace monitoring. In this study, we have considered bioassay method of urine samples. The aim of the study is to analyze the occupational workers internal radioactivity due to manipulation of unsealed sources while treating with the patients for diagnostic and therapeutic purposes.

\section{MATERIALS AND METHODS}

\section{Collection and Preparation of Samples}

Urine samples of a group of seventeen workers, who manipulate radio-nuclides at the National Institute of Nuclear Medicine and Allied Sciences (NINMAS) were collected. Urine samples were collected from occupational workers during 3 to 4 hour after manipulation of $131 \mathrm{I},{ }^{99 \mathrm{mTc}}$ and F-18 in standard plastic pots previously identified with name, date and time of collection (initial and final), activity of handling isotope. Workers were advised to read collecting instructions provided together with the pots. The main concern in this method is to reduce the possibility of external contamination of the pots.

Samples were processed immediately after collection and measured with the HPGe (High Purity Germanium Detector) detector system of the Health Physics Division Laboratory, Atomic Energy Centre, Dhaka. The preparation of urine samples for measurement included determination of its volume. The volume of Urine samples was below $350 \mathrm{ml}$. Finally, sample was put inside a plastic bag and positioned on the HPGe detector to perform the measurement. The processing and sample measurements were performed soon after collection in order to minimize radioactive decay. In the present study, 10 transitions or gamma ray lines of the radionuclide ${ }^{152} \mathrm{Eu}$ were used to perform the efficiency calibration. The efficiency calibration curve is shown in Figure 1.

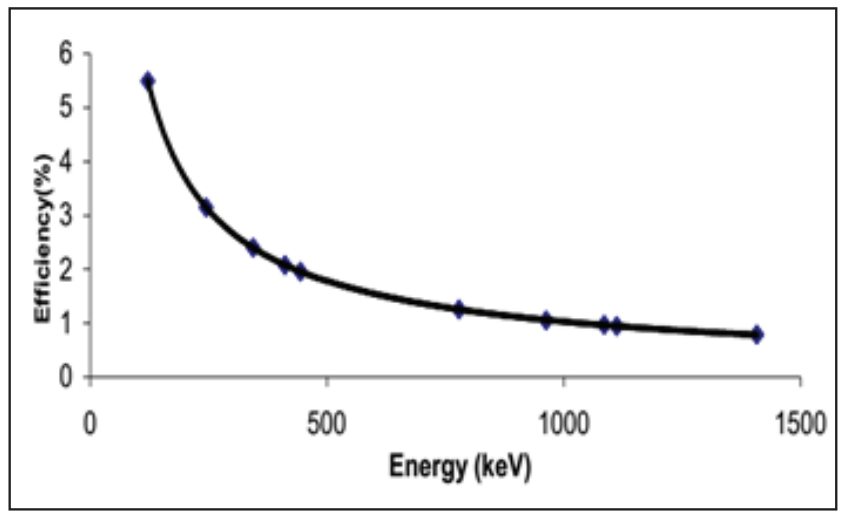

Figure 1: Efficiency of HPGe detector as a function of photon energies

\section{Radioactivity Measurement}

After completing the necessary steps of the HPGe detector, the radioactivity of the samples were measured. HPGe detector was filled with liquid nitrogen at least 12 hours before the measurement and the detector system was turned on 15 minute before the first measurement of each day. The high voltage bias supply to the detector was gradually raised to the operating voltage $(+1600$ Volt.), the amplifier coarse gain, fine gain and peak shaping time were also adjusted to the desired values (3). After all these settings had been done, a period of about half an hour was allowed for stabilization of the system. Then the energy calibration of the detector was checked by placing Cs-137 and Co-60 point sources at the detector axis with a source-to-detector distance of about $20 \mathrm{~cm}$, so that $661.66 \mathrm{keV}, 1170 \mathrm{keV}$, and $1332 \mathrm{keV}$ peaks could appear in the appropriate channels.Figure 2 shows that straight line calibration curve for the gamma sources (137Cs-661.66keV, $40 \mathrm{~K}-1460 \mathrm{keV} \& 60 \mathrm{Co}-1173$ \& $1332 \mathrm{keV})$.



Figure 2: Energy Calibration curve of HPGe detector 
Then a background spectrum was obtained by placing an empty plastic container on the top of the well-shielded detector head for 5000 seconds. After taking the background reading, each of the sample-filled plastic containers was placed on top of the detector head and then the entrance door to the shielding arrangement was closed. The sample's counts were acquired for 5000 seconds. The computer software "Mestro-32" was used to transform the data of each sample. The analysis sheet contained the energy of emitted gamma photons and the corresponding counts per second including the statistical error. After searching for the particular radionuclide's peak and taking the corresponding counts per sec, the total activity for the particular sample was calculated by the following equation

$$
A=\frac{C 100 \times 1000}{\varepsilon E \times P \times V}\left[B q^{-1}\right]
$$

Where, $\mathrm{C}$ is net counts per second, $\varepsilon(\mathrm{E})$ is efficiency of the detector at that energy $\mathrm{E}(\mathrm{keV})$ of the peak easured earlier, $\mathrm{V}$ is volume of Urine in milliliter $(\mathrm{mL}), P_{Y}=$ the photon energy emission probability at energy $\mathrm{E}(\mathrm{keV})$ (6-7).

\section{Evaluation of committed effective dose}

The committed effective dose and the committed equivalent dose can be calculated as follows

$$
H_{A}=\sum_{j} I_{A J}^{h}{ }_{A J}
$$

Where, $H_{A}$ is the committed effective dose or the committed equivalent dose (Sv) by inhalation, $H_{A J}$ is the inhalation dose coefficient $(\mathrm{Sv} / \mathrm{Bq})$ for the effective dose or for the target organ considered for the radionuclide $j$.

For an acute intake at time $t$ before the measurement, the activity of the radionuclides inhaled can be calculated by

$$
I_{A j}=\frac{R j}{r a A j^{(t)}}
$$

Where, $I_{a A j}$ is the activity $(\mathrm{Bq})$ of the radionuclide $j$ inhaled by a member $R j$ is the whole body the activity of the radionuclides $j$ or the activity of the radionuclide $j$ in the organ considered, obtained by indirect measurement $(\mathrm{Bq}), r_{a A j}$ is the fractional activity in total body or in the organ considered at time $t$ after an acute inhalation a of the radionuclide $j$ by a member (8-10)

\section{RESULTS}

A group of seventeen workers, who handle radionuclides at NINMAS has been monitored for identification and quantification of ${ }^{131} \mathrm{I},{ }^{99 \mathrm{mTC}}$ and F-18 in urine samples and 86 urine samples were collected from occupational workers during the year 2017. Figure 3 shows the energy spectrum of an urine sample. Three


$\mathrm{keV}$ (131I) and $1460 \mathrm{keV}$ (K-40). Among these radionuclides $\mathrm{K}-40$ is found naturally in human body. No peak of F-18 is observed. Measured activity of 131I and the corresponding effective doses for different urine samples are listed in Table 1. It is observed that the activity of ${ }^{131} \mathrm{I}$ in 11 samples out of 26 is lower than the minimum detection level.

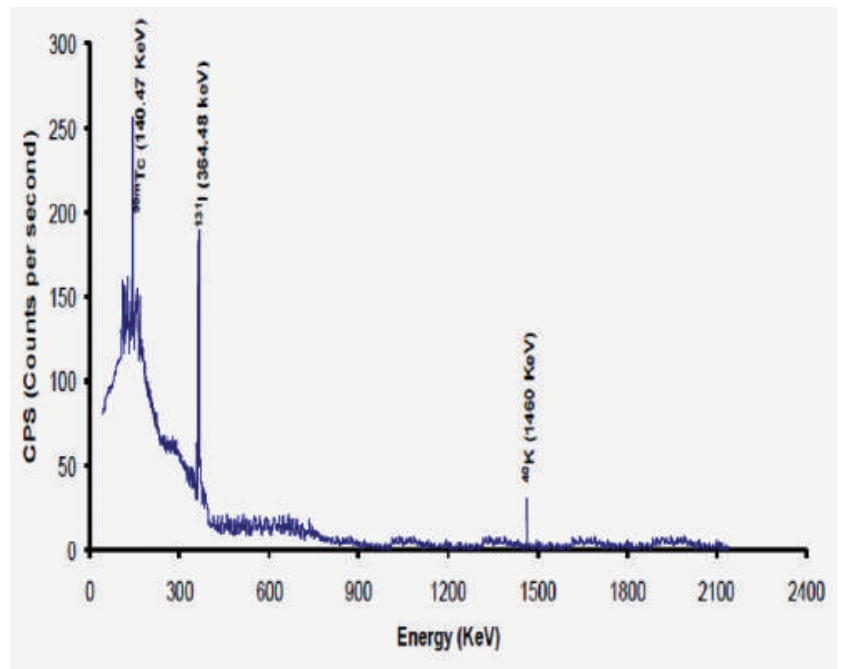

Figure 3: Gamma Energy Spectrum of a Urine Sample

The highest and lowest detected radioactivity concentrations of 131 I in urine samples were $444 \pm 39.91$ $\mathrm{BqL}^{-1}$ and $2.21 \pm 0.44 \mathrm{BqL}^{-1}$ respectively, whereas the highest and the lowest detected radioactivity concentrations of $99 \mathrm{~m} \mathrm{Tc}$ in urine samples were $603 \pm$ $72.36 \mathrm{~Bq}^{-1}$ and $5.53 \pm 1.12 \mathrm{BqL}^{-1}$ respectively. Table 2 contains the measured activity of $99 \mathrm{mTc}$ and the effective doses for a total of 47 urine samples. Only 6 samples have activity lower than minimum detection level. Radioactivity of F-18 was found below the Minimum Detection level in the urine samples of the 
occupational workers who handled F-18 sources, due to low activity of the unsealed F-18 sources and for proper shielding.

Table 1: Measured Activity and Effective Dose of ${ }^{131}$ I in Urine Samples

\begin{tabular}{|c|c|c|}
\hline $\begin{array}{l}\text { Worker } \\
\text { No }\end{array}$ & $\begin{array}{l}\text { Measured } \\
\text { Activity of } \\
131 \mathrm{I}\left(\mathrm{BqL}^{-1}\right)\end{array}$ & $\begin{array}{c}\text { Effective } \\
\text { Dose of } \\
131 \mathrm{I}(\mu \mathrm{Sv})\end{array}$ \\
\hline 1 & MDL & 0 \\
\hline 2 & $9.92 \pm 1.98$ & $1.95 \mathrm{E}-01$ \\
\hline 3 & $10.5 \pm 2.1$ & $2.07 \mathrm{E}-01$ \\
\hline 4 & $110 \pm 13.22$ & $2.17 \mathrm{E}+00$ \\
\hline 5 & $151 \pm 30.26$ & $2.98 \mathrm{E}+00$ \\
\hline 6 & $4.03 \pm 0.81$ & 7.93E-02 \\
\hline 7 & $4.45 \pm 0.89$ & $8.76 \mathrm{E}-02$ \\
\hline 8 & MDL & 0 \\
\hline 9 & $3.06 \pm 0.61$ & $6.02 \mathrm{E}-02$ \\
\hline 10 & MDL & 0 \\
\hline 11 & MDL & 0 \\
\hline 12 & $2.21 \pm 0.44$ & $4.35 \mathrm{E}-02$ \\
\hline 13 & MDL & 0 \\
\hline 14 & MDL & 0 \\
\hline 15 & MDL & 0 \\
\hline 16 & $280 \pm 33.59$ & $5.51 \mathrm{E}+00$ \\
\hline 17 & MDL & 0 \\
\hline 18 & MDL & 0 \\
\hline 19 & MDL & 0 \\
\hline 20 & $9.63 \pm 1.93$ & $1.90 \mathrm{E}-01$ \\
\hline 21 & $304 \pm 33.45$ & $5.99 \mathrm{E}+00$ \\
\hline 22 & $12.37 \pm 2.47$ & $2.43 \mathrm{E}-01$ \\
\hline 23 & MDL & 0 \\
\hline 24 & $29.93 \pm 5.98$ & $5.89 \mathrm{E}-01$ \\
\hline 25 & $444 \pm 39.92$ & $8.73 \mathrm{E}+00$ \\
\hline 26 & $354 \pm 31.80$ & $6.95 \mathrm{E}+00$ \\
\hline
\end{tabular}

MDL= Minimum Detection Limit
Table 2: Measured Activity and Effective Dose of 99mTc in Urine Samples

\begin{tabular}{|c|c|c|}
\hline $\begin{array}{l}\text { Worker } \\
\text { No }\end{array}$ & $\begin{array}{c}\text { Measured } \\
\text { Activity of } \\
\text { 99mTc in BqL-1 }\end{array}$ & $\begin{array}{c}\text { Effective } \\
\text { Dose of } \\
\text { 99mTc in } \mu \mathrm{Sv} \\
\end{array}$ \\
\hline 1 & MDL & 0 \\
\hline 2 & $5.53 \pm 1.12$ & $2.58 \mathrm{E}-01$ \\
\hline 3 & MDL & 0 \\
\hline 4 & $39.36 \pm 7.87$ & $1.84 \mathrm{E}+00$ \\
\hline 5 & $47.76 \pm 9.55$ & $2.24 \mathrm{E}+00$ \\
\hline 6 & $39.72 \pm 7.94$ & $1.86 \mathrm{E}+00$ \\
\hline 7 & $48.4 \pm 9.68$ & $2.27 \mathrm{E}+00$ \\
\hline 8 & $24.08 \pm 4.82$ & $1.13 \mathrm{E}+00$ \\
\hline 9 & $27.63 \pm 5.53$ & $1.29 \mathrm{E}+00$ \\
\hline 10 & $28.51 \pm 5.72$ & $1.34 \mathrm{E}+00$ \\
\hline 11 & $31.86 \pm 6.73$ & $1.49 \mathrm{E}+00$ \\
\hline 12 & $21.7 \pm 4.34$ & $1.02 \mathrm{E}+00$ \\
\hline 13 & $13.93 \pm 2.78$ & $6.53 \mathrm{E}-01$ \\
\hline 14 & $12.7 \pm 2.54$ & $5.95 \mathrm{E}-01$ \\
\hline 15 & $8.41 \pm 1.68$ & $3.94 \mathrm{E}-01$ \\
\hline 16 & $7.61 \pm 1.52$ & $3.57 \mathrm{E}-01$ \\
\hline 17 & $302 \pm 36.24$ & $1.41 \mathrm{E}+01$ \\
\hline 18 & $271 \pm 32.52$ & $1.27 \mathrm{E}+01$ \\
\hline 19 & $275 \pm 33.04$ & $1.29 \mathrm{E}+01$ \\
\hline 20 & MDL & 0 \\
\hline 21 & $64.62 \pm 7.75$ & $3.03 \mathrm{E}+00$ \\
\hline 22 & $64.44 \pm 7.73$ & $3.02 \mathrm{E}+00$ \\
\hline 23 & $58.66 \pm 7.04$ & $2.75 \mathrm{E}+00$ \\
\hline 24 & $61.69 \pm 7.29$ & $2.89 \mathrm{E}+00$ \\
\hline 25 & $60.76 \pm 6.40$ & $2.85 \mathrm{E}+00$ \\
\hline 26 & $29.44 \pm 3.53$ & $1.38 \mathrm{E}+00$ \\
\hline 27 & $294 \pm 35.28$ & $1.38 \mathrm{E}+01$ \\
\hline 28 & $260 \pm 31.02$ & $1.22 \mathrm{E}+01$ \\
\hline 29 & $277 \pm 33.24$ & $1.30 \mathrm{E}+01$ \\
\hline 30 & $42.73 \pm 8.55$ & $2.00 \mathrm{E}+00$ \\
\hline 31 & MDL & 0 \\
\hline 32 & $35.05 \pm 7.01$ & $1.64 \mathrm{E}+00$ \\
\hline 33 & $34.71 \pm 6.94$ & $1.63 \mathrm{E}+00$ \\
\hline 34 & $355 \pm 70.12$ & $1.66 \mathrm{E}+01$ \\
\hline 35 & $368 \pm 44.16$ & $1.72 \mathrm{E}+01$ \\
\hline 36 & $305 \pm 51.06$ & $1.43 \mathrm{E}+01$ \\
\hline 37 & $255 \pm 51$ & $1.19 \mathrm{E}+01$ \\
\hline 38 & MDL & 0 \\
\hline 39 & $456 \pm 54.72$ & $2.14 \mathrm{E}+01$ \\
\hline 40 & $484 \pm 58.08$ & $2.27 \mathrm{E}+01$ \\
\hline 41 & $597 \pm 71.64$ & $2.80 \mathrm{E}+01$ \\
\hline 42 & $517 \pm 62.04$ & $2.42 \mathrm{E}+01$ \\
\hline 43 & $575 \pm 69.01$ & $2.69 \mathrm{E}+01$ \\
\hline 44 & $603 \pm 72.36$ & $2.82 \mathrm{E}+01$ \\
\hline 45 & MDL & 0 \\
\hline 46 & $209 \pm 25.08$ & $9.78 \mathrm{E}+00$ \\
\hline 47 & $172 \pm 20.64$ & $8.07 \mathrm{E}+00$ \\
\hline
\end{tabular}




\section{DISCUSSION}

Due to contamination of $99 \mathrm{mTc}$, the highest effective dose was $28.2 \mu \mathrm{Sv}$ and the lowest effective dose was $0.258 \mu \mathrm{Sv}$. On the other hand, the highest effective dose was $8.73 \mu \mathrm{Sv}$ and the lowest effective dose was $0.0435 \mu \mathrm{Sv}$ due to intake of 131.

The effective doses of occupational staff due to inhalation and contamination of ${ }^{131} \mathrm{I}$ and $99 \mathrm{mTc}$ radionuclides were found low in comparison with annual effective dose of an occupational staff which is $20 \mathrm{mSv}$. The results of concentrations and doses can contribute to improving through regulations and deciding the radiological policies for the internal dosimetry of the radiation staff handling the radioisotopes in the medical fields. Figure 4 compares the average effective dose of $131 \mathrm{I}$ and $99 \mathrm{mTc}$ with the annual dose limit. It is clear from this figure that the effective doses are much lower than the dose limit. Exposure to manmade sources of radioisotopes used in various areas of civilization has both risks and benefits and the whole world is trying to balance these two by following the ALARA (As Low As Reasonably Achievable) principle, designed to minimize radiation doses and releases of radioactive materials.

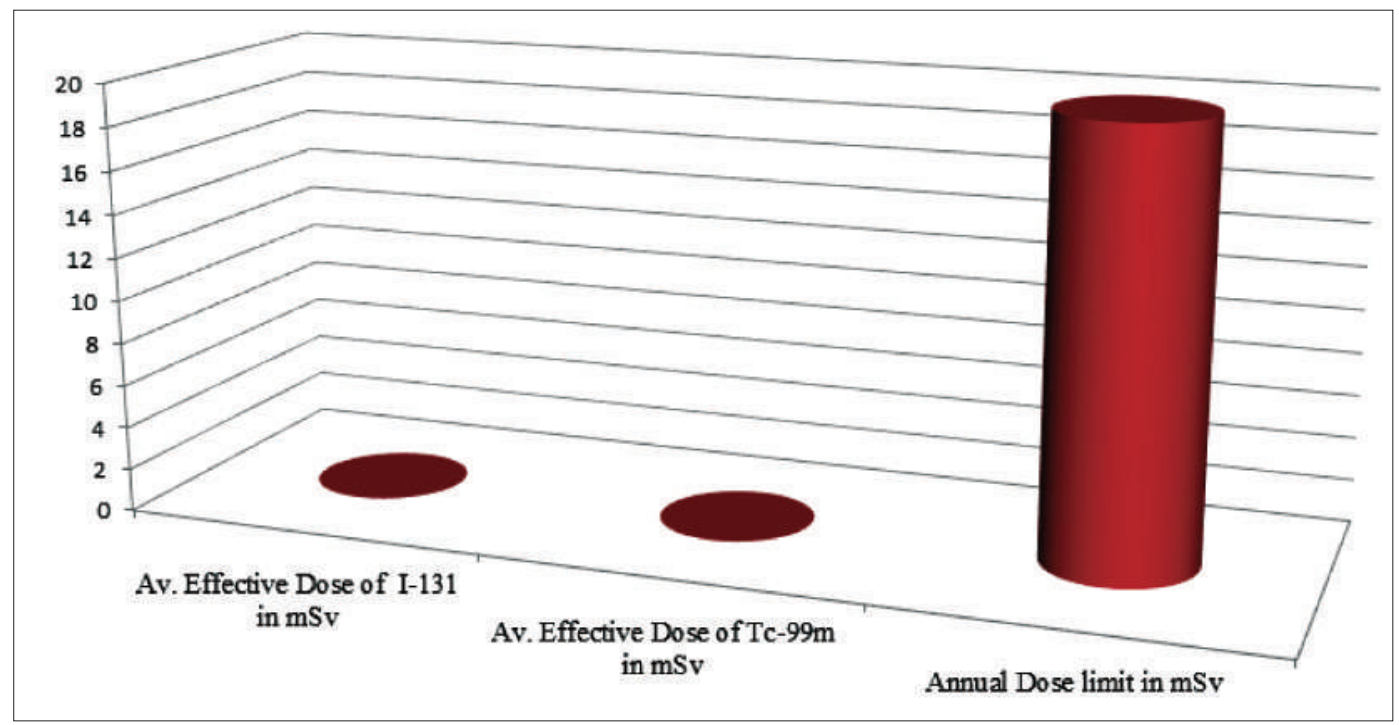

Figure 4: Comparison of Average Effective Dose of 131I and 99mTc with Annual Dose Limit

\section{CONCLUSION}

The experimental results showed that the procedures on internal monitoring are very useful for the control of radiation in NM workers who handle unsealed radioactive sources, in particular inhalation of $131 \mathrm{I}$ and contamination of $99 \mathrm{mTc}$ and F-18. Our study showed that occupational radiation hazards for the NM workers in Bangladesh are mention ably low as the doses they deal with are much below the International Commission on Radiological Protection (ICRP) recommended annual dose limit of $20 \mathrm{mSv}$, which reflects their efforts to abide the ALARA principle.

\section{REFERENCES}

1. Furhang EE, Chui CS, Sgouros G. A Monte Carlo approach to patient-specific dosimetry. Medical physics. 1996 Sep;23(9):1523-9.

2. Johnson TE, Birky BK. Health physics and radiological health. Lippincott Williams \& Wilkins; 2012 Oct 9.

3. Ferdous J, Hossain S, Begum F, Hoque MD. Assessment of activity concentration and effective doses from bioassay sample of occupational workers in NINMAS, Bangladesh. Int J RadiolRadiatTher. 2016;1(2):00008.

4. Dantas BM, Lucena EA, Dantas ALA. Internal exposure in nuclear medicine: Application of IAEA Criteria to Determine the Need for Internal Monitoring, Braz. arch. biol. technol. 2008 Dec;51.

5. Ferdous MJ, Alam Z, Khan RK, Iqubal SM, Islam A. Internal Radiation monitoring of occupational staff in Nuclear medicine facility. Bangladesh Journal of Medical Physics 2012;5(1): 63- 70.

6. KnollF. Radiation Detection and Measurement. John Wiley and sons Inc.2nded.USA. 1989.

7. Engert T. Surface characterization and surface protection of germanium detector crystals. The University of Liverpool (United Kingdom); 2010.

8. Iqubal SM. Calculation of Radiation Doses from Intake of Radionuclides. PhD thesis, National University Gazipur. 2011.

9. International Commission on Radiological Protection, Age-dependent Doses to Members of the Public from Intake of Radionuclides: Part 4 Inhalation Dose Coefficients. ICRP Publication.Pergamon Press. 71. 1995.

10. International Commission on Radiological Protection, Individual monitoring for internal exposure of workers. ICRP Publication.Pergamon Press. 78. 1997. 